\title{
Early Outcome of Transannular Patch Repair of Tetralogy of Fallot With or without Pericardial Monocusp in Pulmonary Position
}

Ahmed Abdelaal Aboufandoud ${ }^{1}$ MSc, El Husseiny El Husseiny Gamil ${ }^{2}$ MD, Monir Osman Amin ${ }^{3}$ MD, Mohamed Eldesouky Sharaa ${ }^{2}$ MD, Al Sayed Mahmoud Salem MD ${ }^{1}$, Mohamed Elsayed Mosa ${ }^{2}$ MD

* Corresponding Author:

Ahmed Abdelaal Aboufandoud

fandood2014@gmail.com

Received for publication March 14, 2020; Accepted February 23, 2021, Published online February 23, 2021.

Copyright 2021 The Author published by Al-Azhar University, Faculty of Medicine, Cairo, Egypt. All rights reserved. This an openaccess article distributed under the legal terms, where it is permissible to download and share the work provided it is properly cited. The work cannot be changed in any way or used commercially.

doi: $10.21608 /$ aimj.2021.25065.1165

${ }^{1}$ Cardiothoracic Surgery

Department, National Heart Institute

${ }^{2}$ Cardiothoracic

Surgery

Department, Faculty of Medicine, Al-Azhar University Cairo, Egypt.

${ }^{3}$ Cardilogy Department, Faculty of Medicine, Al-Azhar University Cairo, Egypt.

\begin{abstract}
Background: In repair of tetralogy of Fallot (TOF), the use of monocusp to protect the right ventricle from volume overload is debatable.

Aim of the work: study evaluates early outcome of pericardial monocusp in pulmonary position in transannular patch repair (TAP).

Patients and methods: 60 patients underwent TOF repair with TAP from June 2016 to December 2018 in Al-Azhar University Hospital and National Heart Institute, group I thirty patients without pericardial monocusp and group II thirty patients received it in pulmonary position. Results: We had Thirty-four male patients representing (56.66\%). The mean age of our patients was $14.983 \pm 6.533$ months. The mean aortic cross clamp time was statistically shorter in group $\mathrm{I}(\mathrm{P}<0.001)$ without statistical significance in the mean Cardiopulmonary bypass time. Intensive care units stay was significantly shorter in group II than group I. The mean hospital stay in group I was $10.862 \pm 2.248$ days which was longer than group II. In post-operative echo, the mean grade of PR in group I was $3.409 \pm 0.734$ and in group II was $1.654 \pm 0.629$ and the mean TR in group I was $1.955 \pm 0.785$ and in group II was $1.346 \pm 0.485$. In follow up echo, the mean grade of PR was $3.448 \pm 0.686$ while in group II was $2.241 \pm 0.830$ and the mean grade of TR in group I was $1.690 \pm 0.712$ while in group II was $1.345 \pm 0.814$.

Conclusion: A pericardial monocusp in pulmonary position is safe, effective and helps to protect the right ventricle from early hemodynamic consequences when transannular patch repair of TOF is done.

Keywords: Pericardial monocusp; Fallot repair; Transannular patch.

Disclosure: The authors have no financial interest to declare in relation to the content of this article. The Article Processing Charge was paid for by the authors.

Authorship: All authors have substantial contributions to the article
\end{abstract}

\section{INTRODUCTION}

Tetralogy of Fallot (TOF) and associated variants represents about $10 \%$ of all forms of congenital heart disease, and TOF is considered the abundant form among cyanotic congenital heart diseases ${ }^{\mathbf{1}}$.

Cooperation between cardiologists and pediatric cardiac surgeons is needed for early diagnosis and proper management in order to improve the outcome and decrease morbidity and mortality ${ }^{2}$. It comprises a wide clinical and anatomical spectrum with different approaches for surgical management. In Patients with smaller right ventricular outflow tract (RVOT) and pulmonary valve annulus a transannular patch is usually needed which can be fashioned simply by autologous pericardium ${ }^{3}$.

Although this repair has the advantage of durability but it acutely renders the status of the right ventricle from being pressure-loaded into volume-loaded ${ }^{4}$.
This result in variable degree of pulmonary insufficiency (PI) that causes temporary and/or delayed RV dysfunction and this chronic RV volume overload can lead to late biventricular dysfunction and tricuspid insufficiency necessitating the need for pulmonary valve insertion ${ }^{\mathbf{5 , 6}}$.

In order to eliminate volume overload, in the short term, some groups have advocated monocusp valve insertion ${ }^{7}$. A number of materials including pericardial, synthetic membrane, and homograft monocusp valves have been used in an attempt to mitigate the free PI associated with simple transannular patching $\mathbf{8 , 9}$.

This study aims to evaluate the early outcome of pericardial monocusp placement in pulmonary position during repair of tetralogy of Fallot when transannular patch (TAP) is indicated.

Our Primary end point was to determine the effectiveness and safety of Insertion of a pericardial monocusp placement in the pulmonary position 
during tetralogy of Fallot repair if transannular patch is indicated .

The Secondary end points are; the intensive care unit stay, the hospital stay, grade of pulmonary valve regurgitation and grade of tricuspid valve regurgitation.

\section{PATIENTS AND METHODS}

Type of the study: This is a prospective, comparative, non-randomized, non-blinded, multicenter cohort study.

Place of settings: Al-Azhar University Hospital and National Heart Institute.

Patient population: Sixty patients underwent surgical correction of tetralogy of fallot by means of transannular patch repair with the following criteria:

Inclusion criteria: Age between six months and twelve years, both sexes and McGoon ratio equal or more than $1.6 / 1$.

Exclusion criteria: Redo cases, Abnormal coronary anatomy and associated major congenital cardiac defects like atrioventricular canal, and absent pulmonary valve.

Ethical consideration: The local Ethical Committee approved the study. Consent was taken from the patients' families prior to enrollment in the study.

Methods: This study was conducted in the period from June 2016 to December 2018. Patients were divided into two groups. Group I: thirty patients didn't receive pericardial monocusp in the pulmonary position. Group II: thirty patients received it in the pulmonary position.

All patients were offered full history taking, clinical examination, routine preoperative laboratory investigations, electrocardiography, and transthoracic echocardiography. Multislice CT and angiography were done in selected cases.

All patients were approached via median sternotomy under general anesthesia with endotracheal intubation. Dissection of the thymus gland with removal of one or both lobes for better exposure if needed. Then generous pericardiectomy taking care not to injure the phrenic nerves.

The harvested pericardium was treated with $0.6 \%$ gluteraldehayde solution for ten minutes to be used for right ventricular outflow tract (RVOT) reconstruction and monocusp fashioning. This was followed by anatomy inspection, heparin administration, routine PDA or ligamentum ligation then conduction of cardiopulmonary bypass (CPB) via aorto-bicaval cannulation with systemic cooling to $28^{\circ} \mathrm{C}$. After the aorta was cross-clamped, cold crystalloid cardioplegia was administered and repeated every 30 minutes, in conjunction with topical ice saline slush. Trans-atrial approach was used for initial assessment and VSD closure using Gor-tex patch with continuous sutures. When a transannular patch was decided, the RVOT was then approached through the tricuspid valve then via a limited infundibulotomy either without insertion of pericardial monocusp in the pulmonary position in group I or with monocusp placement using the previously taken pericardium in group II.

The technique of pericardial monocusp insertion: We can insert a monocusp valve in any sized patient when the monocusp leaflet is tailored (hand-made) to fit the RVOT that is enlarged by a transannular outflow patch. We fashion the previously gluteraldehyde-treated pericardium as hemi-oval shape. The dimensions of the pericardial monocusp leaflet are measured by a ruler or fashioned over a proper size Hegar dilator or any other feasible method like using silk. The length of the monocusp is determined by measuring the length of the incision from the right ventricle to the pulmonary annulus. The width is measured by holding the horizontal edges of the incision open by stay stitches. The monocusp is sewn with 6-0 polypropylene suture over the proximal half of the RVOT incision. Then trans-annular patch is sewn across the entire RVOT onto the main PA with a second suture line using 6-0 polypropylene stitch. In order to ensure monocusp coaptation to the conal septum and/or residual pulmonary valve tissue, the width and length of the monocusp are kept mildly redundant.

Then closure of any identified PFO or atrial septal defect if present, weaning of CPB, obtaining medical and surgical hemostasis, closure of sternum, and transfer of the patient to the intensive care unit (ICU) mechanically ventilated.

Operative reported data were; Cardio-pulmonary bypass time, aortic cross-clamp time, right ventricular pressure post-repair, central venous pressure post-repair and inotropic support used.

Postoperative data included; mechanical ventilation time, ICU stay, pre-discharge \& after six months follow up echocardiography, hospital stay and mortality.

\section{Statistical analysis:}

Data were analyzed using Statistical Program for Social Science (SPSS) version 20.0. Quantitative data were expressed as mean \pm standard deviation (SD). Qualitative data were expressed as frequency and percentage. Independent-samples t-test of significance was used when comparing between two means. Chi-square (X2) test of significance was used in order to compare proportions between two qualitative parameters. Probability P-value $<0.05$ was considered significant.

\section{RESULTS}

The mean age of our patients in group I was $15.633 \pm 8.904$ and in group II was $14.333 \pm 4.163$ months. The mean body weight in group I was $9 \pm 1.702 \mathrm{~kg}$, while in group II it was $9.883 \pm 2.12$ without statistical significance between both groups. 
Echocardiography was routinely performed preoperatively to all patients that showed; similar mean pulmonary annulus diameters in both groups around $0.790 \pm 0.202 \mathrm{~cm}$. The mean McGoon ratio was also similar in both groups without significant difference. Also, there was no statistical difference regarding pressure gradient across RVOT in both groups.

Intra-operatively; the mean cross clamp time showed statistical significance between two groups with $\mathrm{P}<0.001$. Table (1)

\begin{tabular}{|c|c|c|c|c|c|c|c|}
\hline & \multicolumn{5}{|c|}{ Type of procedure } & \multicolumn{2}{|c|}{ T-Test } \\
\hline & \multicolumn{2}{|c|}{ Without monocusp } & \multicolumn{3}{|c|}{ With monocusp } & $\mathrm{t}$ & P-value \\
\hline $\begin{array}{c}\text { Aortic CX } \\
\text { time (Minutes) } \\
\end{array}$ & & & & & & & \\
\hline Range & 43 & 78 & 52 & - & 95 & & \\
\hline Mean \pm SD & 51.600 & \pm 9.961 & 67.76 & \pm & 14.263 & -5.090 & $<0.001 *$ \\
\hline
\end{tabular}

Table 1: Aortic Cross clamp time.

The cross clamp time didn't affect the mean cardiopulmonary bypass time which was $77.467 \pm 15.956$ in group $I$ and $84.167 \pm 9.931$ minutes in group II with no statistical significance $(\mathrm{P}=0.056)$.

The pressure values in right ventricle and the central venous pressure (CVP) post repair were not statistically significant between the two groups.

Postoperatively; the mechanical ventilation time showed no statistical significance despite being shorter in group II. The mean ICU stay time in group I was statistically higher than in group II with $\mathrm{P}=0.021$. The mean hospital stay showed statistical significance between two groups, $\mathrm{P}<0.001$. Figure (1)

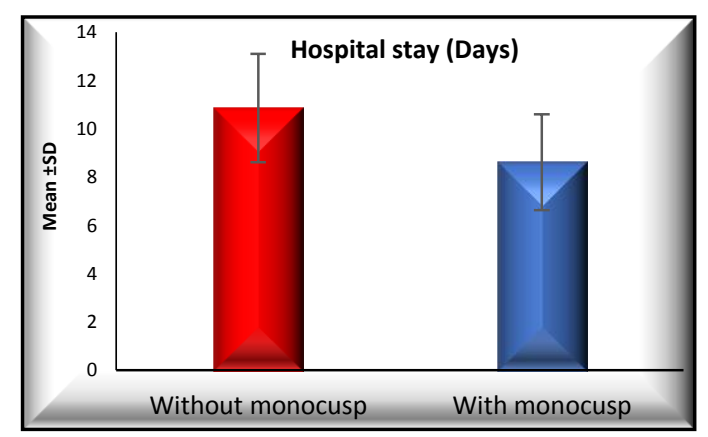

Fig. 1: Hospital utilization.

In pre-discharge echocardiography; the mean grade of pulmonary regurgitation was significantly higher in group I than group II with $\mathrm{P}<0.001$. Also the mean grade of tricuspid regurgitation was significantly higher in group I than group II ( $\mathrm{P}=0.002)$. Table (2)

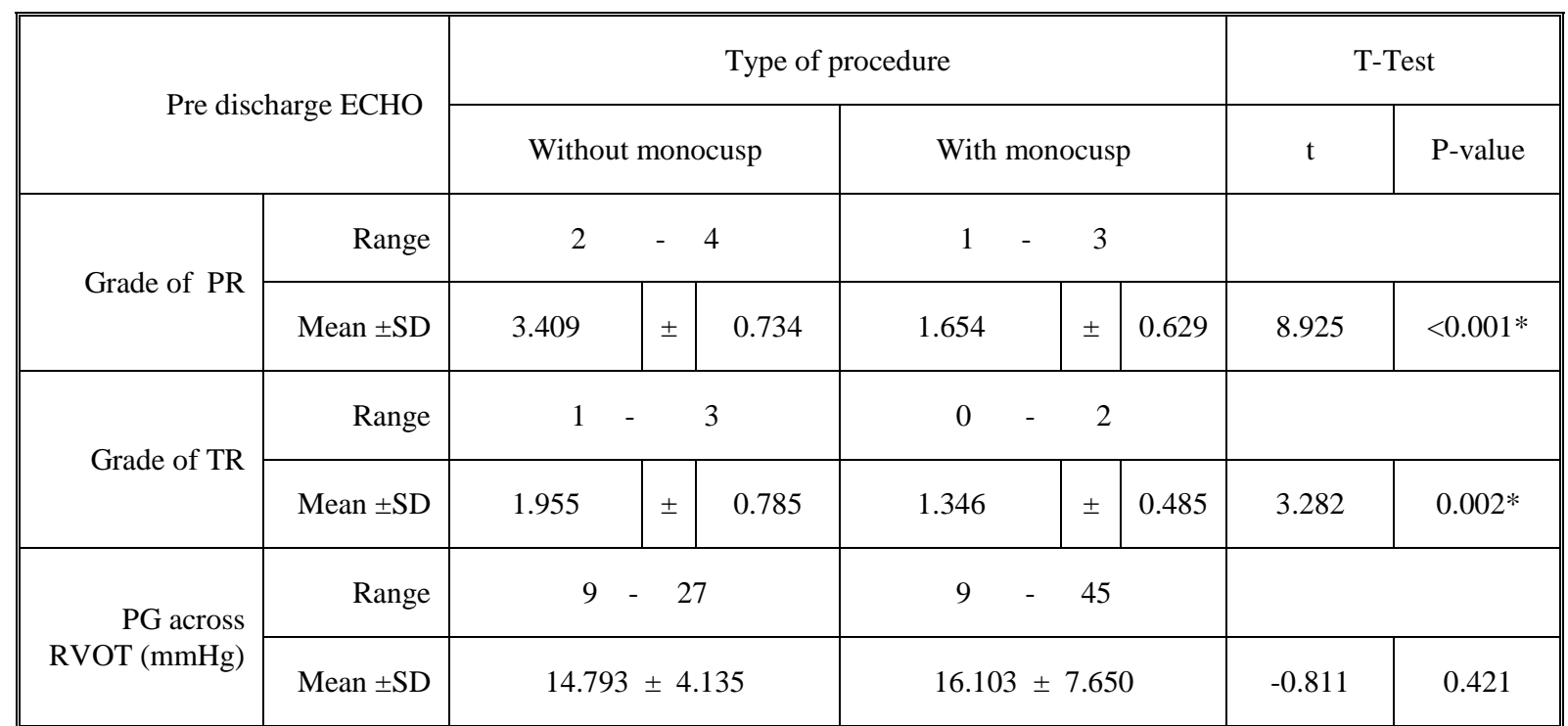

Table 2: Pre-discharge ECHO:

Regarding pressure gradient across RVOT there was no statistical significance between the two groups $(\mathrm{P}=0.421)$. In group I; it ranged between 9-27 mmHg with mean \pm SD $14.793 \pm 4.135$. While in group II; its ranged between 9-45 with mean \pm SD $16.103 \pm 7.650$. That favors the monocusp in the early postoperative period. Table (2) 
higher than in group II with $\mathrm{P}<0.001$ for the sake of group II and the mean grade of TR in group I was
$1.690 \pm 0.712$. While in group II was $1.345 \pm 0.814$ without statistical difference. Table (3)

\begin{tabular}{|c|c|c|c|c|c|c|c|c|c|}
\hline \multirow{2}{*}{\multicolumn{2}{|c|}{ Follow up ECHO }} & \multicolumn{6}{|c|}{ Type of procedure } & \multicolumn{2}{|c|}{ T-Test } \\
\hline & & \multicolumn{3}{|c|}{ Without monocusp } & \multicolumn{3}{|c|}{ With monocusp } & $\mathrm{t}$ & $\mathrm{P}$-value \\
\hline \multirow{2}{*}{$\begin{array}{c}\text { Grade of } \\
\text { PR }\end{array}$} & Range & 2 & - & 4 & 1 & - & 3 & & \\
\hline & Mean \pm SD & 3.448 & \pm & 0.686 & 2.241 & \pm & 0.830 & 6.034 & $<0.001 *$ \\
\hline \multirow{2}{*}{ Grade of TR } & Range & 1 & - & 3 & 1 & - & 3 & & \\
\hline & Mean \pm SD & 1.690 & \pm & 0.712 & 1.345 & \pm & 0.814 & 1.717 & 0.092 \\
\hline \multirow{2}{*}{$\begin{array}{c}\text { PG across } \\
\text { RVOT } \\
(\mathrm{mmHg})\end{array}$} & Range & 10 & - & 25 & 11 & - & 34 & & \\
\hline & Mean \pm SD & \multicolumn{3}{|c|}{$15.773 \pm 3.779$} & \multicolumn{3}{|c|}{$20.34 \pm 5.796$} & -3.172 & $0.003 *$ \\
\hline
\end{tabular}

Table 3: Follow up ECHO

Although the mean pressure gradient across RVOT in follow up echo was statistically lower in group I than in group II $(\mathrm{P}=0.003)$, it was within acceptable levels in group II with mean PG around 20 mmHg.Table (3) And none of our patients required reoperation for valve complications during the follow up period.

In our study we had five mortalities representing $8.33 \%$ of our total patients, three patients $(5 \%)$ in group I two of them developed low cardiac output state in the ICU with subsequent irreversible renal shutdown despite increasing the inotropic support and the third patient could not be weaned of cardiopulmonary bypass due to right ventricular failure and declared dead in the operation theatre. In group II we had two mortalities $(3.33 \%)$ one of them was due to low cardiac output state that ended in biventricular failure and the other one was due to intractable arrhythmia in the form of heart block and low cardiac output state with renal failure. This is demonstrated by Kaplan Meier curve. Figure (2)

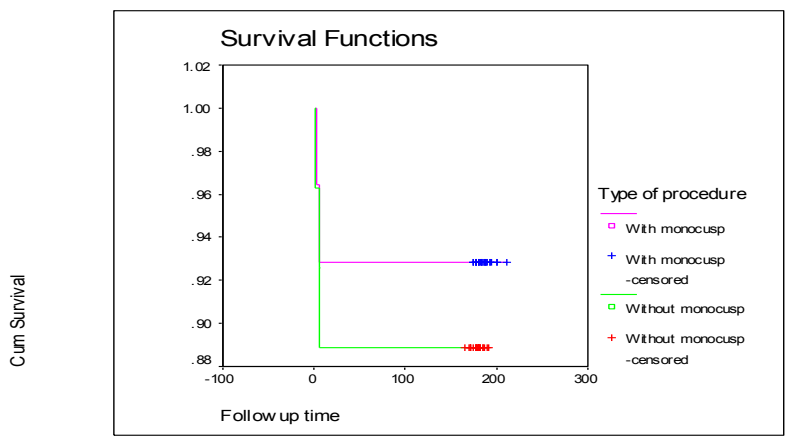

Fig. 2: Kaplan Meier curve.

\section{DISCUSSION}

Tetralogy of Fallot is considered to be one of the most common cardiac malformations, representing approximately around 3 to 5 per 10,000 live births and it's the most common of the cyanotic cardiac lesions (TOF, transposition of the great arteries, total anomalous pulmonary venous return, and Tricuspid atresia) ${ }^{10}$.

Pulmonary insufficiency is an unwarranted side effect of the transannular patch used for relieving the right ventricular outflow tract obstruction that is characteristic of tetralogy of Fallot ${ }^{10}$. In order to eliminate volume overload, in the short term, some groups have advocated monocusp valve insertion ${ }^{7,8}$.

Demographic profiles were well matched between group I and group II in our patients. No significant differences were noted with respect to gender, age at time of operation. This is a little bit dissimilar to Turrentine and colleagues who studied 158 patients who underwent surgical procedures for management of severe RVOT ${ }^{12}$.

The mean age of our patients was 15 months with range of six months to three years, but no neonates were operated in either group when compared to Jacek Kolcz and Christian Pizarro who published their results including 66 cases of Fallot Tetralogy, they had 46 out of them were neonates and 20 patients were infants ${ }^{13}$.

The aortic cross clamp time was significantly higher in the monocusp group (group II) of our patients with mean of 67 minutes while the transannular patch group (group I) showed mean aortic cross clamp time of 51 minutes. This represents the time needed for monocusp insertion in the pulmonary position. This was similar to Turrentine et al. ${ }^{12}$. The cross clamp 
time difference between the two groups didn't affect the $\mathrm{CPB}$ time which showed no statistical significance between our two groups, while Turrentine et al. found a longer CPB time in monocusp group which was against our results. The net result favors the monocusp technique, although the mean time for cross-clamp is higher in the monocusp group because no difference in the overall time needed for the repair ${ }^{12}$.

In our study, we preferred to do monocusp placement in the pulmonary position while the heart is completely flaccid then declamping the aorta, as it has no influence on the patients' outcome, avoiding back flow from collaterals and in order to secure suture line. In-contrast to our technique, Soliman A. preferred reconstruction of the RVOT while the aortic cross clamp is removed to reduce the ischemic time ${ }^{14}$.

The ICU stay time was significantly lower in the monocusp group because fewer patients necessitated either high or prolonged intravenous inotropic support with subsequent time needed for weaning and discharge from ICU, these results match with other series $^{12,15}$.

Our results showed statistically significant difference between two groups in pre-discharge echo regarding the grade of pulmonary valve and tricuspid valve regurgitation. This was near to Sasson L. and colleagues who found those patients who underwent complete repair with monocusp implantation did not show any significant deterioration in the severity of PI at home discharge ${ }^{15}$. This favors the monocusp technique.

Our outcome matches Turrentine et al, who found significant difference in the incidence of pulmonary insufficiency with only mild to moderate RVOT regurgitant flow in monocusp patients with no statistical difference between their patients regarding TR grade ${ }^{12}$. Also Nath et al reported no change from the hospital discharge values for the peak systolic gradient across the RVOT ${ }^{16}$.

Mortality in our study was $8.33 \%$ of our patients. This was near Mostafa Ezzeldin A. and Elmidany Ashraf A. who stated that perioperative mortality rate when total repair of uncomplicated cases of tetralogy of Fallot is done is less than 5\% ${ }^{17}$. Our study also was near to Brown et al who reported 9 deaths representing 5\% out of 192 patients ${ }^{7}$ and near to Nath et al, who had a mortality of about $4.3 \%$ among their series ${ }^{16}$.

Study limitations: the major limitation of our study is the small number of patients in a two-center experience and the use of one material only which is the pericardial monocusp.

We recommend the conduction of a multi-center study on larger number of patients with longer periods of follow up to thoroughly evaluate the effect of monocusp insertion on the outcomes after repair of tetralogy of Fallot with transannular patch and using other materials like PTFE.

\section{CONCLUSION}

Insertion of a pericardial monocusp in the pulmonary position is safe and effective. It is favorable regarding the ICU and hospital stay with good results of pulmonary and tricuspid valve regurgitations. Its overall outcome is better when compared to transannular patch only during repair of tetralogy of Fallot.

\section{REFERENCES}

1. Stewart RD, Mavroudis $\mathrm{C}$ and Backer CL. Tetralogy of Fallot. In: Mavroudis C, Backer CL, editors. Pediatric Cardiac Surgery. $4^{\text {th }}$ ed. New Jersey: Wiley-Blackwell, 2013; 410-12.

2. El-Sayegh TM, El-Saegh MM, Shoeb MA, et al. Open heart surgery in the first 2 years of life. Egypt Heart J, 1993; 43: 89-94.

3. Kouchoukos NT, Blackstone EH, Hanley FL, et al. Kirklin/ Barratt- Boyes Cardiac Surgery. $4^{\text {th }}$ ed. Philadelphia (PA): Elsevier, 2013; p. 1362400.

4. Kaza AK, Lim HG, Dibardino DJ, et al. Longterm results of right ventricular outflow tract reconstruction in neonatal cardiac surgery: options and outcomes. J Thorac Cardiovasc Surg, 2009; 138: 911-6.

5. Wald RM, Redington AN, Pereira A, et al. Refining the assessment of pulmonary regurgitation in adults after tetralogy of Fallot repair: should we be measuring regurgitant fraction or regurgitant volume? Eur Heart J, 2009; 30: 356-61.

6. Ilbawi MN, Idriss FS, DeLeon SY, et al. Factors that exaggerate the deleterious effects of pulmonary insufficiency on the right ventricle after tetralogy repair. Surgical implications. $J$ Thorac Cardiovasc Surg, 1987; 93: 36-44.

7. Brown JW, Ruzmetov M, Vijay P, et al. Right ventricular outflow tract reconstruction with a polytetrafluoroethylene monocusp valve: a twelve-year experience. $J$ Thorac Cardiovasc Surg, 2007; 133: 1336-43.

8. Vogt PR, Genoni M, Kunzli A, et al Cryopreserved homograft monocusp valves for reconstruction of the right ventricular outflow tract. J Thorac Cardiovasc Surg, 1997; 113: 423.

9. Bogers AJ, Roofthooft M, Pisters H, et al. Longterm results of the gamma-irradiation-preserved homograft monocusp for transannular reconstruction of the right-ventricular outflow tract in tetralogy of Fallot. Thorac Cardiovasc Surg, 1994; 42: 337-9. 
10. Alexiou C, Chen Q, Galogavrou M, et al. Repair of tetralogy of Fallot in infancy with a transventricular or a transatrial approach. Eur $J$ Cardiothorac Surg, 2002; 22: 174-83.

11. Kang IS, Redington AN, Benson LN, et al. Differential regurgitation in branch pulmonary arteries after repair of tetralogy of Fallot: a phase-contrast cine magnetic resonance study. Circulation, 2003; 107(23): 2938-43

12. Turrentine MW, McCarthy RP, Vijay $\mathrm{P}$, et al. PTFE Monocusp Valve Reconstruction of the Right Ventricular Outflow Tract. Ann Thorac Surg, 2002; 73: 871-80.

13. Kolcz $\mathrm{J}$ and Pizarro C. Neonatal repair of tetralogy of Fallot results in improved pulmonary artery development without increased need for re-intervention. Eur J Cardio-Thorac Surg, 2005; 28:394-9.
14. Soliman A Soliman. Tetralogy Of Fallot repair without Ventriculotomy, thesis for partial fulfillment of MD in cardio-thoracic surgery. 1995; 1-238.

15. Sasson L, Houri S, Raucher Sternfeld A, et al. Right ventricular outflow tract strategies for repair of tetralogy of Fallot: effect of monocusp valve reconstruction. European Journal of Cardio-Thoracic Surgery, 2013; 43:743-51.

16. Nath DS, Nussbaum DP, Yurko C, et al. Pulmonary Homograft Monocusp Reconstruction of the Right Ventricular Outflow Tract: Outcomes to the Intermediate Term. Ann Thorac Surg 2010; 90:42-9.

17. Mostafa EA and Elmidany AA, Ain Shams Lecture Notes on Cardiovascular and Thoracic Surgery. Vol. 2: Congenital Heart Surgery. Egypt: Elnasr Publishing Co for Digital Education, 2016. p. 142. 